\title{
Fatigue cracks and stress amplitude analysis of orthotropic steel deck in a suspension bridge
}

\author{
Zhuoyi Chen ${ }^{a}$, Chuanxi $\mathrm{Li}^{\mathrm{b}}$ and $\mathrm{Lu} \mathrm{Ke}^{\mathrm{c}}$ \\ Changsha University of Science \& Technology, Changsha 410114, China

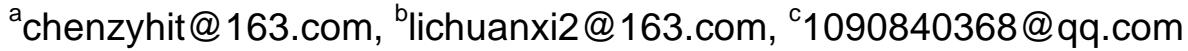

Keywords: Steel box girder; orthotropic steel deck; fatigue crack; transverse crossbeam; cope hole.

Abstract. Four kinds of fatigue cracks are found in a suspension bridge with orthotropic steel deck. Finite element analysis was conducted to investigate the reason of fatigue cracks originated from the cope hole in the transverse crossbeams. The stresses surround the cope holes in the crossbeam are calculated under vehicle loads which are imposed on scheduled positions on the bridge deck. Then the relationship between the peak stresses surround cope hole and the loading position is acquired. There are 2 areas have the effects of stress concentration surround a cope hole, which are named area-A and area- $\mathrm{B}$. The calculation results indicate that the peak stress in area-A is greater than the allowed fatigue stress-range under 2 million cyclic loads, and the actual position of fatigue crack detected in the bridge is coincide with the position of area-A.

\section{Introduction}

Orthotropic steel decks are used for their high strength and light weight, and have become very frequently used in construction of long span bridge such as suspension bridges and cable stayed bridges. As the experience accumulate, the details of the structure become more reasonable than before and the manufacture process of orthotropic steel deck has been improved. Such as the trend to increase the thickness of the deck plate from $12 \mathrm{~mm}(\mathrm{Hu}$ Men bridge, Jiang Yin bridge, Hai Cang bridge) to $14 \mathrm{~mm}$ (Run Yang bridge, Xi Houmen bridge), then the thickness increase to $16 \mathrm{~mm}$ (Ping Sheng bridge, Jia shao bridge), and even increase to 18mm (Tao Huayu Yellow River bridge, Gang Zhu Ao bridge)[1-4]. In Severn Bridge the transverse crossbeam cut-through the longitudinal ribs and there were several cracks generated in crossbeam to longitudinal rib welds. Then the transverse crossbeam turn into disconnected and cope holes are leaved in the crossbeam to longitudinal rib afterwards [5]. At the same time, the full penetration welds are widespread used in U-ribs to deck slabs weld instead of overlay welding, and the joints of vertical ribs of web to deck slabs were canceled[6,7]. Though several kinds of cracks are avoided, there still have some kinds of fatigue cracks in orthotropic steel decks nowadays.

A suspension bridge, which has serviced for 8 years, is introduced in this paper. Four kinds of fatigue cracks are found in this bridge. The cracks originate from the cope hole in crossbeam are analyzed specially. FED models for orthotropic steel deck of this suspension bridge are built to prove the fatigue problem of orthotropic steel deck can be avoided effectively under the condition that the structure detail is reasonable, the design method is scientific and the thickness of steel slab is sufficient. Also the structural optimization of the cope hole in orthotropic steel deck will be introduced in this paper.

\section{Project profile}

A self-anchored suspension bridge with single tower is presented, the structural style in main span of which is the orthotropic steel deck. The height of the steel box girder in the main span is $3.5 \mathrm{~m}$, and the roof is $16 \mathrm{~mm}$ thick. The section size of the longitudinal $U$ shape ribs of the orthotropic steel deck are $300 \times 280 \times 10 \mathrm{~mm}$ with the thickness of $10 \mathrm{~mm}$, and there center distances are $600 \mathrm{~mm}$. The thickness of 
the transverse crossbeam in the suspension center and un-suspension center are $12 \mathrm{~mm}$ and $10 \mathrm{~mm}$ respectively.

The fatigue cracks in orthotropic steel deck of this bridge can be divided into 4 types: (1)Crack originate from the cope hole in crossbeam; (2) Crack location in trough to crossbeam weld; (3) Crack location in rib of web to deck slab weld; (4) Crack location in crossbeam to deck slab weld.

The cracks originate from the cope hole in crossbeam are found in this bridge with the quantity of 121. Their distribution characteristic as below: 1) This kind of cracks mainly locates in the crossbeam under heavy lane, and few of them locate in the crossbeam under fast traffic lane. There is no this kind of crack found in the crossbeam under the overtaking lane and the slow-traffic lane, as shown in Fig.1. It indicates that the cracks originate from the cope hole are connected with the weight and the number of the vehicles. 2) This kind of cracks mainly locates in the crossbeam with the thickness of $10 \mathrm{~mm}$. In $10 \mathrm{~mm}$ thick crossbeam, this kind of cracks account for $95 \%$ of the total amount, and the cracks in $12 \mathrm{~mm}$ thick crossbeam account for $5 \%$ of the total amount. It indicates that this kind of cracks relate to the thickness of crossbeams.

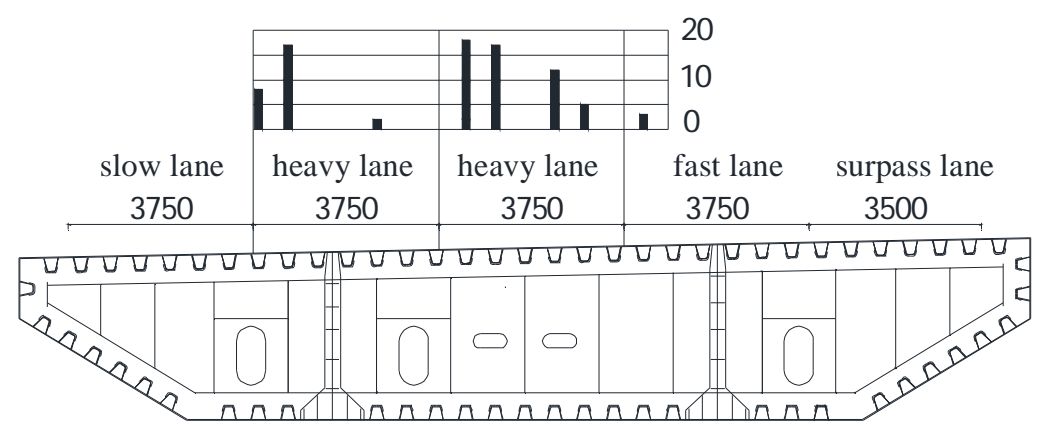

Fig.1 Structure and crack statistics of steel box girder in left

The number of the crack location in trough to crossbeam weld were found in the orthotropic deck is 5, which is shown in Fig.2 (b). For this kind of crack relates to the quantity of weld and this cracks develope slowly, repair welding with beveling (for vertical cracks) or polishing and remelting (for toe crack) are reasonable methods to repair this kind of cracks.

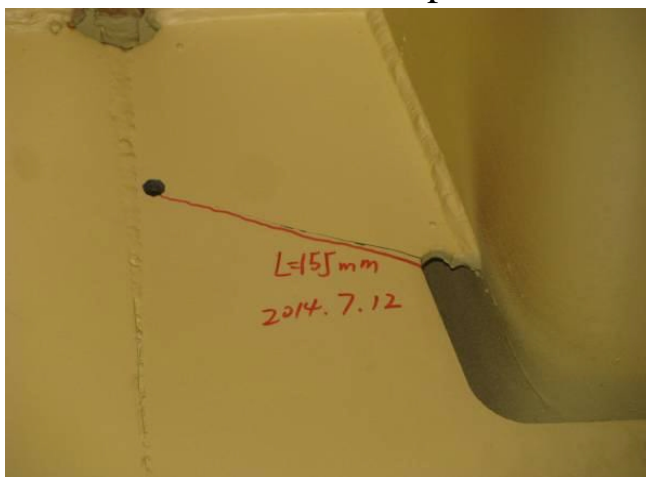

(a) Crack originate from the cope hole in crossbeam

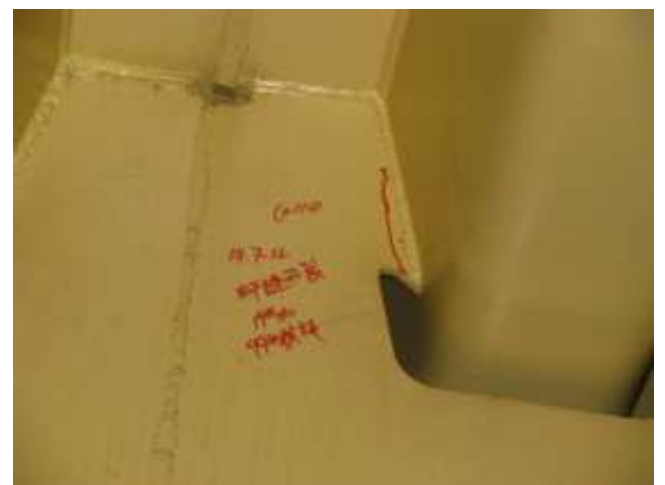

(b) Crack location in trough to crossbeam weld

Fig. 2 Two kinds of fatigue cracks

\section{Fatigue crack analysis}

Two assumptions are adopted in this calculation, which as follow: 1) the material mechanics properties of structures or members are all in elastic range. 2) The constraint from the suspender cable to the steel box girder is rigidity supporting.

A $550 \mathrm{kN}$ standard vehicle with the after axle load of $140 \mathrm{kN}$ is used. According to the tire 
touchdown area $(0.2 \mathrm{~m}$ long and $0.6 \mathrm{~m}$ width) and the thickness of bridge deck pavement $(5 \mathrm{~cm})$, the effective action area of the steel deck slab is a rectangle with the size of $0.3 \mathrm{~m} \times 0.7 \mathrm{~m}$. The uniform load is $0.33 \mathrm{MPa}$. It is shown in Fig5.The FEA model of box steel girder is built by common finite element software ABAQUS (V6.10). The meshes near the cope hole in the transverse crossbeam are refined to $0.2 \mathrm{~mm}$, for the stress concentrate in this area. And when the mesh seizes refined to $0.2 \mathrm{~mm}$, the calculation error is less than $0.2 \%$. The model with refined mesh contains about 640 thousand plate element (S4R).As is shown in Fig.3.

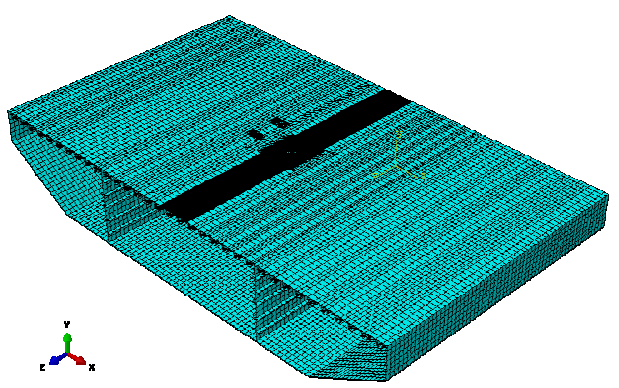

(a) The whole model

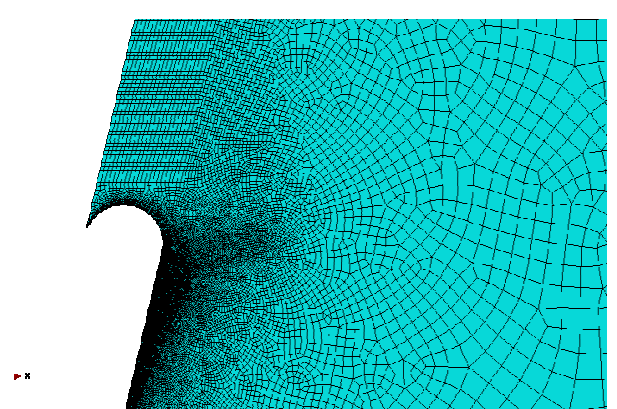

(b) Local model of cope hole area

Fig. 3 FEM of box steel girder

To certify the most unfavorable condition and obtain the relationship between the stress of crossbeam surrounding the cope hole and the position of vehicle loading, the loading scheme is confirmed as follow: 1) lateral moving the loading position. 2) Longitudinal moving the loading position. Four loading schemes are analyzed, which include longitudinal position 1, longitudinal position 2, transverse position 1 and transverse position 2. As shown in Fig.4.

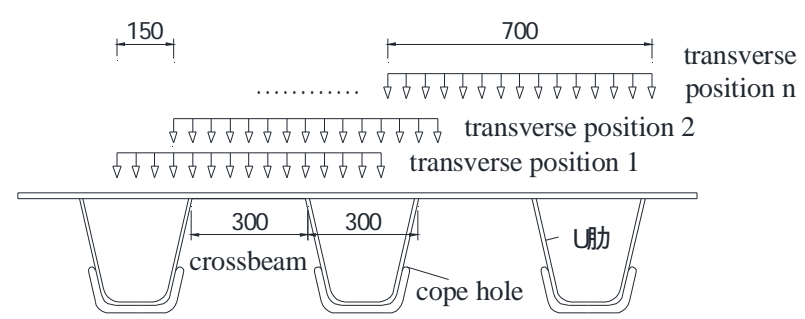

(a)Transverse position of left wheel

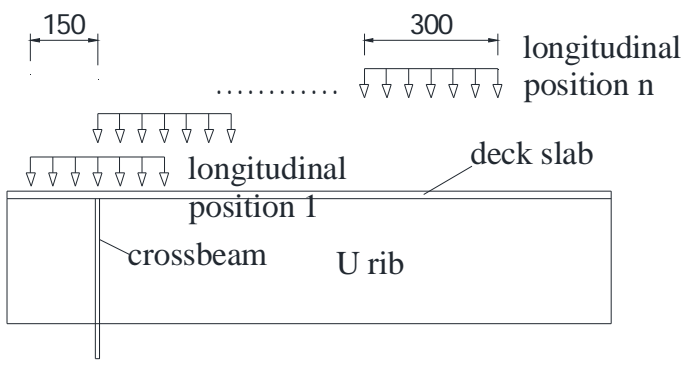

(b) Longitudinal position of left wheel

Fig.4 loading method

The calculating results show in the Figure 5 (a) that: 1) as the center of wheel load move from the longitudinal location 1 to longitudinal location $n(n>3)$, the maximum stress of area-A of the concerned cope hole increases at first and then drop, when the center of wheel loads in the longitudinal location 3 (the wheel load moves longitudinally $300 \mathrm{~mm}$ ), the maximum stress of area-A is the biggest of all. 2) When the center of wheel load moves to the top of the next piece of diaphragm plate (the wheel load moves longitudinally $3000 \mathrm{~mm}$ ), the maximum stress of area-A of the concerned cope hole is about $10 \mathrm{MPa}$; the influence of the wheel load is small. 3) Along with the wheel load moves laterally, within the distance of $300 \mathrm{~mm}$, the maximum stress of area-A drops at first and then increase; when the wheel load moves transversely more than $300 \mathrm{~mm}$, the maximum stress of Area-A drops rapidly; when the wheel load moves transversely to $750 \mathrm{~mm}$, the maximum stress of area-A is close to 0MPa. 4 ) The maximum stress of area-A is very sensitive to the location of the lateral load, when the distance from the center of wheel load to the horizontal position of cope hole exceed $1.0 \mathrm{~m}$, the influence of the wheel load to the stress of area-A concerned location basically can be ignored. 5) For the influence to the stress of area-A of the concerned cope hole, the influence of longitudinal effect is more extensive than 
lateral effect.

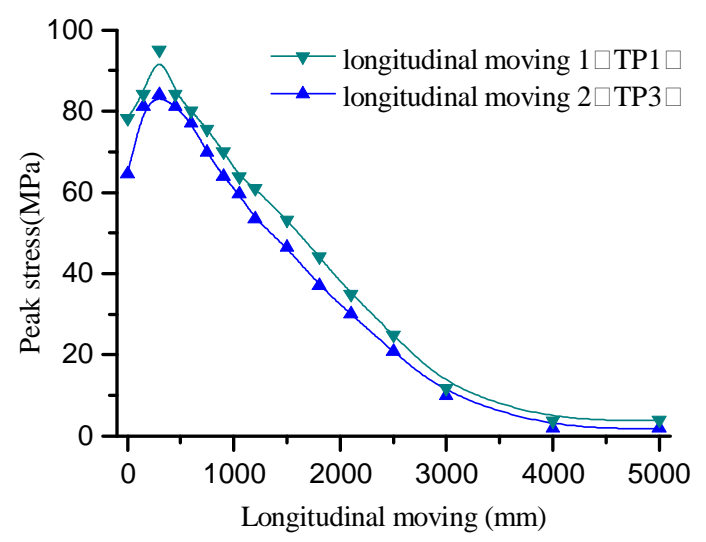

(a) Longitudinal moving

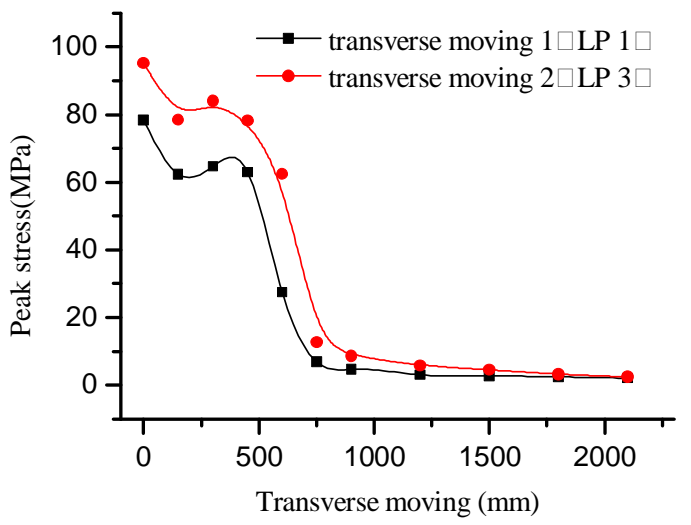

(b) transverse moving

Fig. 5 Stress influence line of region A

The stress nephogram of cope hole area is shown in Figure 6 for the most unfavorable position of wheel loading. Among them, there are two stress concentrated areas, the area-A (the main compressive stress area) and the area-B (the main tensile stress). The equivalent maximum stress of area- $\mathrm{A}$ is $154.2 \mathrm{MPa}$; the equivalent maximum stress of area- $\mathrm{B}$ is $92.0 \mathrm{MPa}$; and the equivalent maximum stress of the location of the diaphragm plate border with $\mathrm{U}$ rib is $54.3 \mathrm{Mpa}$.

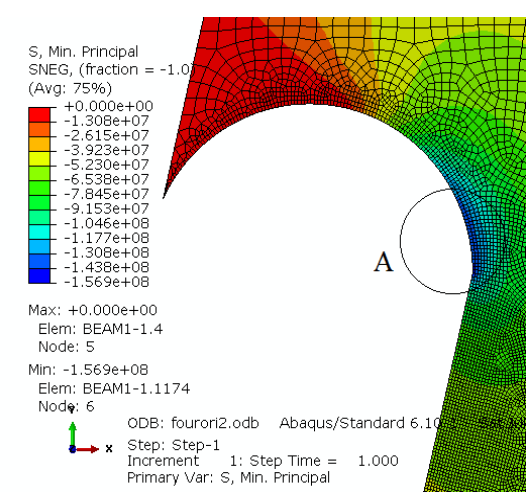

(a) Principal compressive stress (peak is $154.2 \mathrm{MPa}$ )

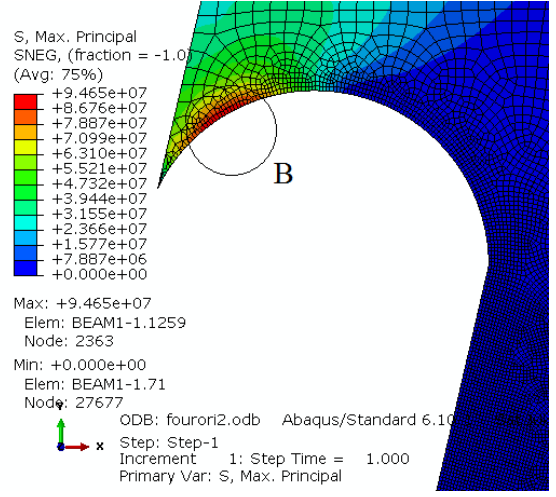

(b) Principal tensile stress (peak is 92.0Mpa)

Fig. 6 The stress nephogram of original design cope hole with calculating load

According to the steel structure design code (GB50017-2003, steel structure third categories of members and connection details 200 million times the allowable fatigue stress amplitude is $118 \mathrm{MPa}$, 1000 million times (no fatigue damage) allowable fatigue stress amplitude is $68 \mathrm{MPa}$; According to the steel structure of railway bridge and culvert design specifications (TB10002.2-2005), steel structure of the sixth component category and connection structure details of 200 million times allowable fatigue stress amplitude for 114MPa. The maximum stress of the concerned cope hole with the action of calculating wheel load $(70 \mathrm{kN})$ is greater than the stress amplitude. Thus, with greater repeated wheel load, the life of cope hole diaphragm plate is limited, running after a certain period of time will craze.

\section{Conclusions}

There are 2 areas have the effects of stress concentration surround a cope hole, which are named area-A and area-B. The calculation results indicate that the peak stress in area-A is greater than the allowed fatigue stress-range under 2 million cyclic loads, and the actual position of fatigue crack detected in the bridge is coincide with the position of area-A. 
The stresses surround the cope holes in the crossbeam are calculated under vehicle loads which are imposed on scheduled positions on the bridge deck. When the center of wheel loads located at the longitudinal location 3, a peak stress is acquired in area-A round the concerned cope hole. When the center of wheel load moves to the top of the next piece of diaphragm plate, the influence of the wheel load is small. The maximum stress of area-A is obtained when the wheel load moves $300 \mathrm{~mm}$ laterally, and when the wheel load moves transversely more than $300 \mathrm{~mm}$, the stress of Area-A drops rapidly. The influence of longitudinal effect is more extensive than lateral effect at the area-A round the concerned cope hole.

\section{Acknowledgements}

This work was financially supported by the Education Department Science Foundation of Hunan (2016093), the National Natural Science Foundation of China (51078078, 51308070), and the Fundamental Research Funds for the Central Universities (15QLTD08)

\section{References}

[1] CONNOR R J, FISHER J W. Journal of Bridge Engineering, ASCE. Vol.11 (2006), p.517.

[2] ZHANG Qinghua, CUI Chuang, BU Yizhi.. China Civil Engineering Journal. Vol.23 (2014), p: 110. (in Chinese)

[3] Connor R J Fisher J W. Journal of Bridge Engineering. Vol.11 (2006), p.517.

[4] Xiao Z G, Yamada K, Ya S, Zhao X L. International Journal of Fatigue. Vol.30 (2008), p.1387.

[5] Tsakopoulos P A, Fisher J W. Journal of Bridge Engineering. Vol.8 (2003), p.323.

[6] Zhao Xinxin, Liu Xiaoguang, Pan Yongjie, China Railway Science. Vol.34 (2013), p.41. (in Chinese)

[7] Song Yongsheng, Ding Youliang, Wang Gaoxin. Journal of Southeast University: Natural Science Edition. Vol.43 (2013), p.403. (in Chinese) 